\title{
Papular eruption on UV-exposed skin in a 7-year-old boy caused by Enterobius vermicularis infection
}

\author{
Mateja Starbek Zorko ${ }^{1,2}$, Anja Trajber Horvat ${ }^{3}$
}

\begin{abstract}
Enterobiasis is the most common parasite infestation in children; it is often asymptomatic and may rarely be a cause of skin eruption. We present the case of a 7-year-old boy with sudden onset of pruritic erythemato-squamous confluent papules and plaques on UV-exposed skin, caused by proven enterobiasis. To our understanding, this is the first case of photodermatosis-like dermatitis caused by enterobiasis reported in the literature.
\end{abstract}

Keywords: child, Enterobius vermicularis, dermatitis, UV-exposed skin

Received: 29 August 2019 | Returned for modification: 16 September 2019| Accepted: 8 October 2019

\section{Case report}

We present the case of a 7-year-old boy with sudden onset of pruritic, well-circumscribed erythemato-squamous macules and papules on his face that progressed to his neck and extremities in a few days. Due to suspicion of bacterial infection, his pediatrician prescribed local gentamicin ointment and systemic antibiotic with penicillin. After 3 days no improvement was seen, and he was sent to a specialist in infectious diseases, who excluded bacterial infection, discontinued antibiotic therapy, and prescribed him antihistamines. Because of a persistent itchy rash, after 1 week he was sent to our outpatient clinic, where, in addition to peroral antihistamines, topical corticosteroid therapy was started. Because of a burning sensation following the application of local corticosteroid cream, the parents discontinued the therapy. After 1 week no improvement was seen, and so he was hospitalized at Department of Dermatovenereology for further diagnostics and treatment.

He had no previous skin problems and was otherwise a healthy child. He was not taking any medication and had no known allergies. There were no skin diseases in his family, but his mother had a known pollen allergy.

At the time of hospitalization confluent, well-demarcated erythemato-squamous papules and plaques on UV-exposed skin (the face, neck, and extremities) and dry, scaly lips were observed (Figs. 1-2). The skin of other parts of the body was unaffected, and his general somatic status was unremarkable.

Apart from eosinophilia (7.1\%, normal range 1-6\%), other laboratory exams-complete blood count, liver enzymes and creatinine, electrolytes, creatine kinase, lactate dehydrogenase, and complete urine analysis-were all within normal limits. Immunoserology (ANA, ENA, and anti-ds DNA) and porphyrins in erythrocytes and urine were all within normal range. Due to the presence of eosinophilia, we suspected either parasitosis or an atopy.

A perianal cellophane swab was positive for Enterobius vermicularis. There was a highly elevated complete IgE (626 kU/1, normal range for a child of 7 years up to $71 \mathrm{kU} / \mathrm{l}$ ) and later positive specific IgEs to wheat, barley, buckwheat, soy, house dust mites, and mixture of grass, tree, and weed pollen were found.
The patient was treated with a single $100 \mathrm{mg}$ dose of the antiparasitic mebendazole, and he continued taking antihistamines systemically because of the pruritus. Once daily we applied wet saline dressings followed by topical methylprednisolone aceponate cream on the affected skin. After 1 week of therapy, his skin lesions regressed completely over the following days (Figs. 3-4) and did not repeat after playing outside or after sun exposure, later that year, and not even the next year.

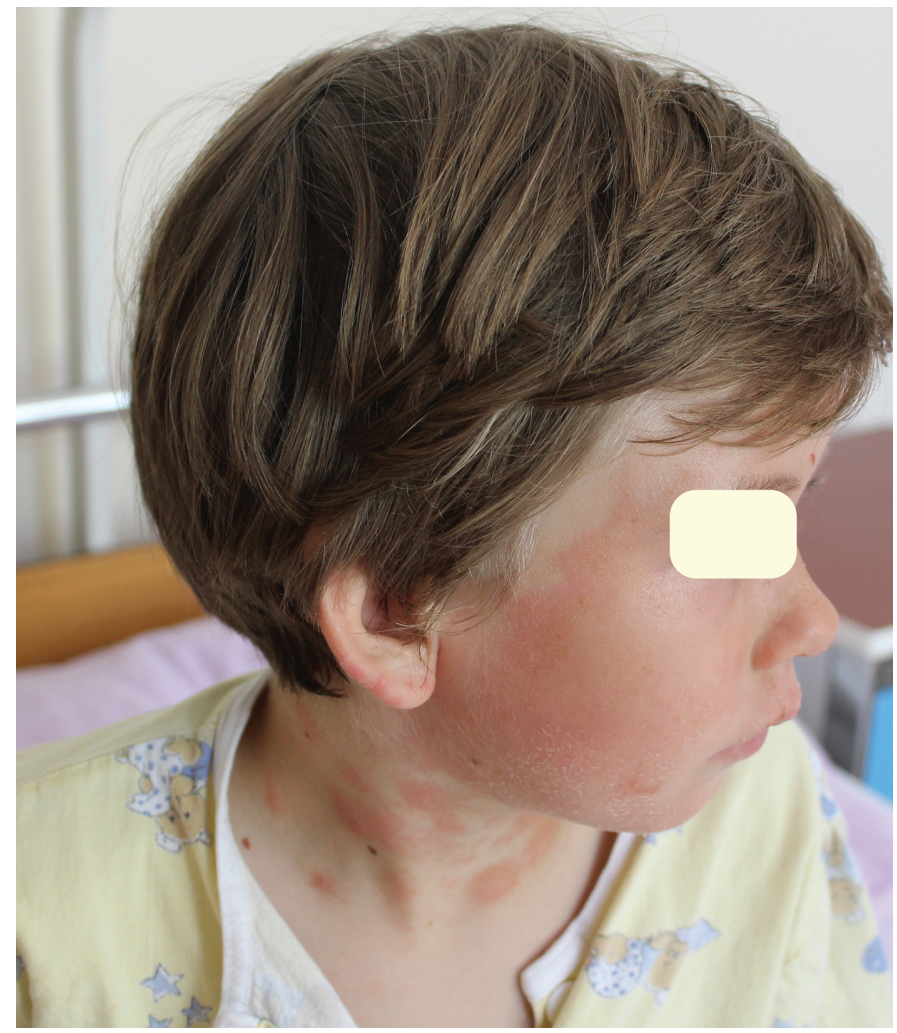

Figure 1 | Erythemato-squamous papules and plaques on the face and neck.

\section{Discussion}

Enterobius vermicularis is an intestinal parasite that is usually transmitted in humans by direct fecal-oral transfer by the hands. 


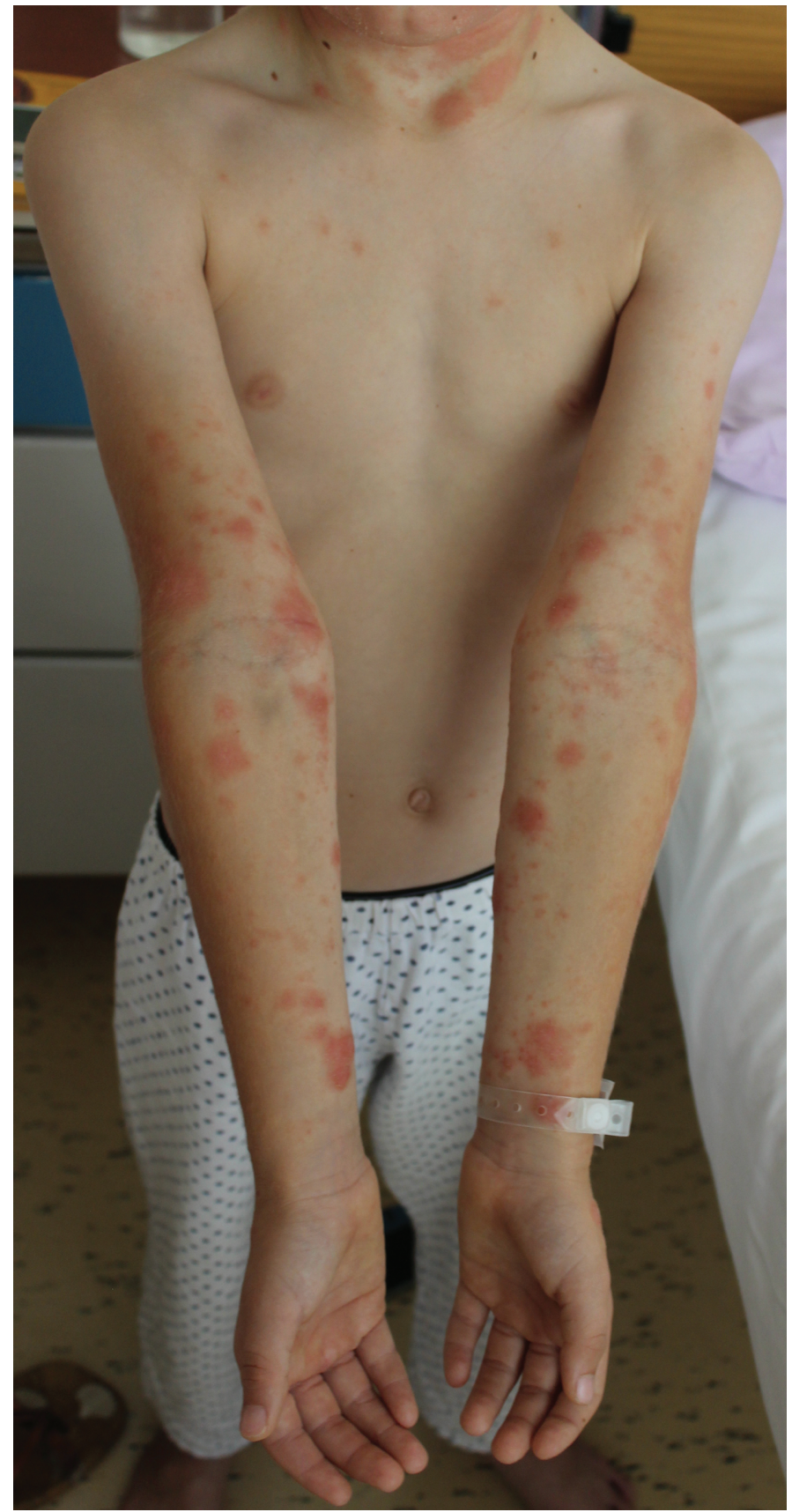

Figure $2 \mid$ Papules and plaques on the skin of the upper extremities.

The pinworm lives in the small intestine and migrates to the perianal area at night, where it deposits eggs. It is the most common nematode infection in school-aged children and due to insufficient hygiene can quickly spread to other family members (1). In adults it can also be transmitted by inhaling or ingesting dust with airborne eggs while changing bedding or handling infested children's clothes (1).

The highest prevalence of enterobiasis (up to 50\%) has been recorded in the United States and northwestern parts of Europe, in various institutions and at summer camps $(1,2)$. The exact prevalence of the infestation in Slovenia is not known, presumably because of inaccurately reported cases, but the results of the last few years show that the prevalence is increasing (3).

Up to one-third of infested patients can be asymptomatic, and others usually present with perianal or perineal pruritus and eosinophilia. In children other non-specific signs such as irritability, restlessness, insomnia, enuresis, anorexia, and weight loss have been reported (2). Infestation with Enterobius vermicularis can also
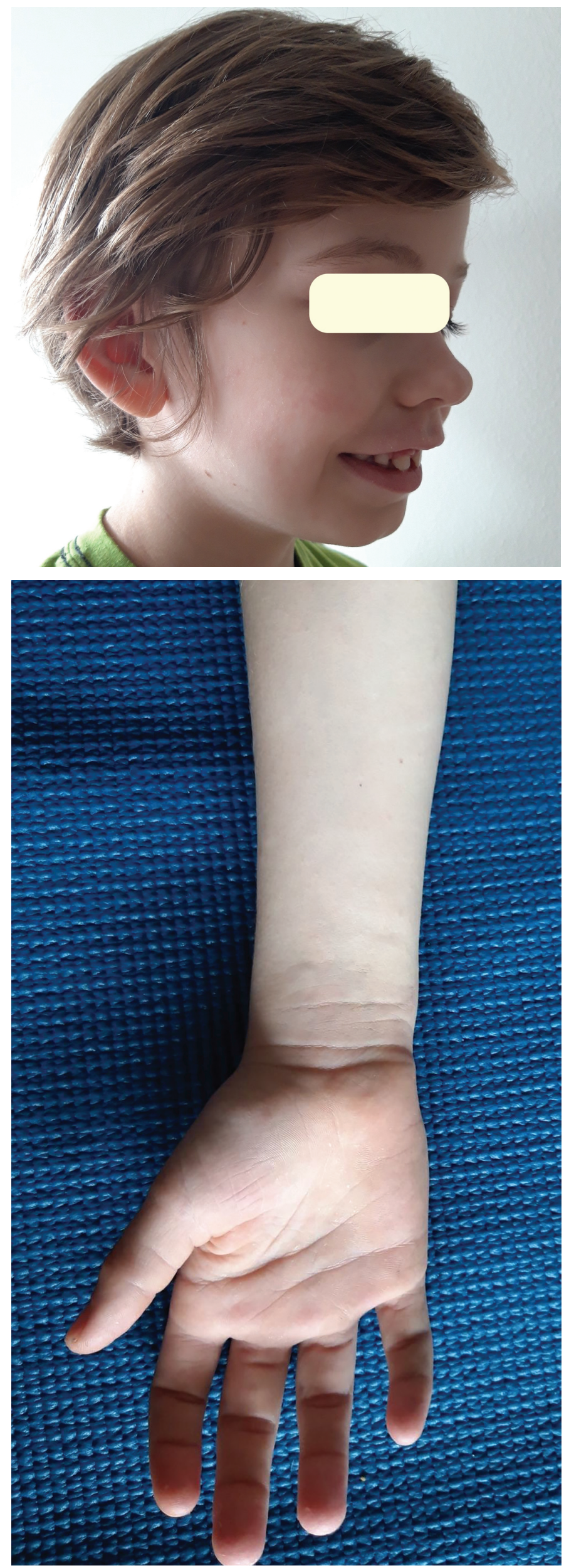

Figure 3 and 4 | Complete regression of skin lesions after treatment. 
cause extra-cutaneous signs, including gastrointestinal symptoms such as diarrhea and rarely appendicitis, diverticulitis, granuloma of the colon, perianal abscess, and ileum perforation $(2,4)$. Due to nocturnal migration of the parasite from the lumen of the gastrointestinal tract, some helminths can invade the genitourinary tract and cause vulvovaginitis, salpingitis, epididymitis, and urinary tract infections $(1,4)$. Enterobius vermicularis infection has rarely been reported as the cause of generalized pruritic dermatitis or even urticaria $(1,2,5,6)$, but none of these reports described eruption only on photo-exposed skin, as seen in our case.

A study in Israel showed that Enterobius vermicularis-induced symptoms were more common in children with underlying dermatoses (e.g., atopic dermatitis, neurodermatitis, contact dermatitis, seborrheic dermatitis, or psoriasis) (2), and a study by Wördemann et al. showed that enterobiasis in Cuban children is a risk factor for allergic rhinoconjunctivitis or atopic dermatitis (7). However, studies investigating the association between Enterobius vermicularis and allergic conditions have shown conflicting results (8). Laboratory findings of eosinophilia and raised IgE suggest invasive disease, whereas infestation limited to the gut mostly does not cause eosinophilia (9). In our patient no perianal or perineal pruritus was noticed, but eosinophilia and raised IgE levels suggested parasitosis. Specific IgE levels confirmed hypersensitivity to several allergens, but up until then our patient had no skin disease and no symptoms suggesting allergic disease.

Enterobious vermicularis infection is usually confirmed by an adhesive tape test showing parasite eggs. Stool analysis for parasites or ova is positive only in 5 to $15 \%(2,5,6)$. As light yellowish threadlike worms, helminths can be found on toilet paper or in the stool (1). In complicated cases, the diagnosis can be made with endoscopy, where pinworms in the distal part of colon can be seen (5).

Although histopathological findings of skin lesions caused by parasitosis are nonspecific (5), we suggested performing a skin biopsy due to the unusual presentation of the skin lesions in our case, but the parents did not agree to this.

Benzimidazole compounds such as mebendazole and albendazole, given orally, are the most effective treatment for enterobiasis $(2,9)$. Due to mebendazole malabsorption, in genitourinary infection the suggested treatment is ivermectin rather than mebendazole $(1,3)$. If a child has enterobiasis, it is recommended that other family members also be treated because they may have an asymptomatic infection. It is also very important to increase personal hygiene, especially hand washing $(2,9)$. Our patient was treated with a single dose of mebendazole, repeated after 2 weeks, as suggested in literature (9). After systemic therapy for infestation and symptomatic therapy for dermatitis, we observed complete regression of the dermatitis, which did not reappear after being outside, exposure to known allergens, or exposure to sun, and so we concluded that Enterobius vermicularis infection was the main cause of the sudden onset of papular eruption on UV-exposed skin.

\section{Conclusions}

Based on our case, we suggest that enterobiasis should be considered in the differential diagnosis of persistent pruritic dermatitis on UV-exposed skin in children with elevated IgE and/or eosinophilia. The diagnosis of infection is easily confirmed by microscopic examination of an adhesive tape test. Treatment with anti-parasite drugs is recommended. One must keep in mind that reinfection is quite frequent, which is why it is very important to treat all family members in order to minimize the possibilities of reinfection. In a child with eruption on UV-exposed skin, one should bear in mind enterobiasis as a possible cause of the rash. With a positive adhesive tape test and the right treatment, it is possible to avoid additional laboratory tests and their costs in order to exclude other causes of photodermatosis.

\section{References}

1. Burkhart CN, Burkhart CG. Assessment of frequency, transmission, and genitourinary complications of enterobiasis (pinworms). Int J Dermatol. 2005;44:83740.

2. Cook GC. Enterobius vermicularis infection. Gut. 1994;35:1159-62.

3. Sočan M. Epidemiološko spremljanje nalezljivih bolezni v Sloveniji v letu 2016 [Internet]. Nacionalni inštitut za javno zdravje, Ljubljana, Slovenia. [cited 17 October 2018]. Available from: http://www.nijz.si/sites/www.nijz.si/files/datoteke/epidemiolosko_spremljanje_nb_slo_2016.pdf. Slovenian.

4. Villarreal O, Villarreal JJ, Domingo JA. Progressive eosinophilia and elevated IgE in enterobiasis. Allergy. 1999;54:646-7.

5. Ni Raghallaigh S, Powell FC. Enterobius vermicularis dermatitis. Clin Exp Dermatol. 2010;35:e32-33.

6. Buslau M, Marsch WC. Popular eruption in helminth infestation-a hypersensitivity phenomenon? Report of four cases. Acta Derm Venereol. 1990;70:526-9.

7. Wördemann M, Diaz RJ, Heredia LM, Collado Madurga AM, Ruiz Espinosa A, Prado RC, et al. Association of atopy, asthma, allergic rinoconjuctivitis, atopic dermatitis and intestinal helminth infections in Cuban children. Trop Med Int Health. 2008;13:180-6.

8. Bøås H, Tapia G, Rasmussen T, Rønningen KS. Enterobius vermicularis and allergic conditions in Norwegian children. Epidemiol Infect. 2014;142:2114-20.

9. Lloyd AE, Honey BL, John MB, Michelle Condren M. Treatment options and considerations for intestinal helminthic infections. J Pharm Technol. 2014;30:130-9. 